удк $34 \mathrm{~T}$

\title{
Г.А. Шокиров
}

\section{ИНФОРМАЦИЯ КАК ОСНОВНОЙ ОБЪЕКТ ИНФОРМАЦИОННЫХ ПРАВООТНОШЕНИЙ: ТЕОРЕТИЧЕСКИЙ И ПРАКТИЧЕСКИЙ АСПЕКТЫ}

\begin{abstract}
Повышение роли информации в обществе связано с развитием фундаментальных и прикладных исследований в разных областях науки, и их соединяет такое понятие, как «информация». Исследуются понятие «информация» в контексте информационного законодательства Республики Таджикистан и его соотношение с информационным законодательством Российской Федерации.

Ключевые слова: информация; информатика; вычислительная техника; информационное право; информационное законодательство.
\end{abstract}

С развитием связи и телекоммуникации, вычислительной техники и их использованием для обработки и передачи информации возникла необходимость измерять количественные характеристики информации. В связи с появлением такого понятия, как «информация», появились разные теории и понятия самой информации. С использованием информации появляются новые правовые отношения - правовые отношения в информационной сфере. В связи с этим основным объектом этих правоотношений является само понятие «информация».

Перед тем как начать анализ проблем по данной теме, раскроем суть понятия «объекты правоотношения». В теории права относительно объекта правоотношений существуют различные точки зрения.

А.С. Пиголкин, А.Н. Головистикова и Ю.А. Дмитриев под объектом правового отношения предлагают понимать материальные и духовные блага, получение и использование которых составляет интерес управомоченной стороны [1. С. 624].

По мнению профессора А.Б. Венгерова, под данной дефиницией понимаются различные блага, которые стремятся получить управомоченные субъекты. По мнению автора, это состояния, которых они стремятся достичь, то поведение, которого они ждут от обязанных субъектов, и т.д. [2. С. 471].

Исследуя данную проблему, профессор Р.Ш. Сативалдыев подчеркивает, что объектом правового отношения являются субъективные права, личные и государственные интересы, материальные и духовные блага, служебная деятельность и их результаты, в связи с которыми возникают правовые отношения [3. С. 561].

Глубоко изучив данную проблему, профессор C.А. Комаров под понятием «объекты правоотношения» понимает явления окружающего мира, по поводу которых возникают субъективные права и субъективные юридические обязанности. Автор выделяет точки зрения относительного понимания данной дефиниции:

1) монистическая точка зрения состоит в том, что объектом правоотношения могут быть только поступки, деяния людей;

2) согласно второй точки зрения (плюралистической), объектом правоотношения могут быть материальные блага (вещи, имущества, ценности и т.п.), нематериальные блага (жизнь, здоровье, честь и достоинство и т.п.), продукты духовной деятельности (произведения искусства, науки музыки, литературы, ком- пьютерные программы и т.п.), ценные бумаги и документы (деньги, акции, дипломы, аттестаты и т.п.), а также результаты действия участников правоотношений [4. С. 330].

Таким образом, на основании высказанных точек зрения в теории права утверждена многоаспектность объектного содержания правоотношений. Единой позиции по данному феномену не существует, а на основании высказанных позиций мы можем определить, что под понятием «объект правоотношений» понимается смысл существования этих правоотношений, почему субъекты права вступают в правовые отношения, действуют в них, реализуя свои права и обязанности. При информационных отношениях объектом правоотношений является сама информация.

Как отмечают С.Г. Чубукова и В.Д. Элькин, действительно, с переходом человечества в качественно новое общество, информационное, жизнь и практическая деятельность в нем неразрывно связаны с освоением и использованием современных информационных технологий. По мнению авторов, сегодня потоки социально-правовой информации, обрушивающиеся на юриста, требуют от него владения информационными технологиями - справочными правовыми системами, юридическими экспертными системами, современными программными и техническими средствами защиты информации, электронной цифровой подписью, информационными технологиями, лежащими в основе функционирования современных компьютерных сетей и глобальной сети Интернет, и т.п. [5. С. 24-25]. И действительно, как утверждают психологи, на сегодняшний день человек разумный превращается в человека информационного. Развитие информационных систем привело к появлению человеко-машинных систем.

В связи с тем что идет активное развитие процессов информатизации общественной и государственной инфраструктуры, появляется необходимость глубокого исследования всех институтов информационного права, и особенно объекта правовых отношений данной отрасли права. Наша основная задача - это определение сущности и содержания понятия «информация». В науке существуют философское, математическо-кибернетическое и правовое толкования понятия «информация».

У философов сложилась устойчивая традиция рассмотрения информации на основе философских категорий отражения и различия (разнообразия). С фило- 
софской позиции толкования, информация не существует как объект без отражения. Приведем мнения некоторых исследователей по поводу данного понятия.

Коллектив авторов (философов) [6. С. 166] дал следующее толкование понятия «информация»: в широком смысле - результат отражения одного объекта в другом, используемый, в конечном счете, для формирования управляющих воздействий. Для понимания сущности понятия «информация» авторы предлагают рассматривать данный феномен в трех аспектах: синтаксическом, семантическом и прагматическом. По их мнению, синтаксическая сторона информации характеризует внутреннюю особенность используемого в управлении «слепка» объекта, его структуру, сложность и организованность. Под семантикой информации понимается то, что она должна обладать определенным смыслом, т.е быть соотнесенной с отражаемым объектом. В прагматическом аспекте, понимается способность информации влиять на процесс управления, т.е. ценность и полезность информации.

Другая группа авторов [7. С. 114-115] (также философов) предлагает следующее толкование понятия информации: информация (лат. information - осведомление) - буквально сведения, данные, знания, центральное понятие кибернетики, обозначающее не только сведения, передаваемые людьми в ходе их общения, но прежде всего одно из основных свойств объективного мира, которое связано с наличием в нем особого рода процессов, называемых информационными.

Исследуя данный феномен, О.А. Гаврилов указывает на то, что «информация» является одной из фундаментальных характеристик мироздания наряду с материей, энергией, пространством-временем. По мнению автора, информация связана с такими свойствами материи, как отражение, структура, разнообразие, и не может существовать вне материального носителя - физического объекта, иного энергетического субстрата или социальных и психологических процессов [8. С. 6].

В науке информатика основные понятия и сущности информации тоже исследованы. Как отмечает Е.Н. Филинов, понятие «информация» является, естественно, центральным в информатике, но до сих пор не имеет четкого и общепринятого определения, его используют главным образом на интуитивном уровне. Цитируя несколько опубликованных работ по данному феномену, автор придерживается той позиции, что определение понятия «информация» является спорным. Он следует определению информации, которое дано в Большой Советской энциклопедии: информация - это сведения, передаваемые одними людьми другим людям устным, письменным или каким-либо другим способом (например, с помощью условных сигналов, с использованием технических средств), а также сам процесс передачи или получения этих сведений. По мнению автора, с точки зрения человека, главным в толковании термина «информация» являются постижение и выражение сущности (смысла) тех сведений, которые он получал [9. С. 13-14].

Выявляя понятие и особые признаки информации, другой специалист в области информатики Ф.С. Во- ройский останавливается на особых свойствах и признаках информации. По его мнению, данный термин и отражаемое им понятие являются сегодня одними из самых распространенных. Они используются как на бытовом, так и на профессиональном уровне. Цитируя мнение различных исследователей, он предлагает следующую сокращенную форму понятия информации: информация - это данные, необходимые или полезные тому, кому они передаются [10. С. 14-18].

Таким образом, на основании предыдущих определений мы можем подытожить, что в философии и информатике под понятием «информация» подразумеваются данные (сведения), которые несут нужную информацию для человека.

Следующая проблема - это анализ мнений исследователей-юристов о понятии и сущности информации как основного объекта информационных правоотношений. В юридической литературе также существуют различные точки зрения по данному понятию.

Тщательно исследовав данный феномен как основной объект информационного права и проанализировав мнения зарубежных авторов, 3.3. Зейналов охарактеризовал информацию следующим образом:

- информация должна существовать в момент правоотношения;

- информация предназначена для физических и юридических лиц и имеет определенное предназначение;

- информация возможна для передачи и размножения;

- информация имеет определенную форму и единицу измерения;

- информация научно обоснована и доказана, в связи с чем может быть предметом судебного спора;

- информация юридически закреплена;

- информация имеет определенный источник и, соответственно, может иметь получателя [11].

По мнению профессора В.А. Копылова, информация является основным объектом в информационной сфере, а Ноберт Винер считает, что философское определение информации для права неприемлемо. Тем самым автор к основным особенностям и свойствам информации относит следующие:

- свойства физической неотчуждаемости информации;

- обособляемости (овеществления) информации;

- информационной вещи (информационного объекта);

- тиражируемости (распространяемости) информации;

- организованной формы;

- экземплярности информации [12. С. 49-50].

С.Г. Чубукова и В.Д. Элькин, сославшись на мнение В.М. Глушкова, А.М. Прохорова, И.И. Юзвишина и др., пишут о том, что причина такой несогласованности подходов к определению информации заключается в том, что данное слово имеет бытовое происхождение и применялось задолго до его проникновения в науку. Тем самым авторы не дают формулировку общего понятия «информация» [5. С. 29-35].

Анализируя данное понятие и его определения, А.В. Минбалеев сообщает о том, что в мире существует несколько моделей легального определения 
понятия «информация». По мнению автора, законодательство одних государств (Великобритания, Швеция и др.) не дает определения информации, используя конструкцию «информация - это информация». В России же и постсоциалистических странах СССР придерживаются позиции закрепления в общих законах понятия «информация», а в законодательстве других государств оно представлено через формы выражения информации (без ее определения), т.е. это данные, текст, образцы, изображения, звуки, коды, компьютерные программы, программное обеспечение, базы данных и т.п. (Сингапур, Гонконг, США, Индия, Ирландия) [13. С. 17].

Вопросам исследования данного феномена посвящено множество работ см., например, [14]. Если анализировать их с юридической точки зрения, как подчеркивает 3.3. Зейналов, то мы с легкостью обнаруживаем, что в основном материалы, изложенные в научной литературе, носят повторный характер [11].

Таким образом, указанные юридические особенности и свойства понятия «информация» должны быть учтены при правовом регулировании информационных отношений. Особенности и юридические свойства информации проявляются в информационных системах и информационных процессах, обеспечивающих реализацию основных информационных прав, провозглашенных в конституционных нормах, и обязанностей соответствующих субъектов в порядке обеспечения гарантий информационных прав и свобод.

В Республике Таджикистан в сфере информационного законодательства понятие «информация» трактуется в трех нормативных правовых актах: в ст. 3 Закона Республики Таджикистан «Об информатизации» [14] от 06.08.2001, в ст. 1 Закона Республики Таджикистан «Об информации» [15] от 10.05.2002 и в ст. 2 Закона Республики Таджикистан «О праве на доступ к информации» [16] от 18.06.2008. Если проанализировать суть самого понятия, то почему-то законодатель в трех нормативных правовых актах Республики Таджикистан определил их по-разному [17. С. 29-30].

Такую же трактовку мы наблюдаем и в законодательстве Российской Федерации. Согласно ч. 1. ст. 2 Федерального закона от 27 июля 2006 г. № 149-Ф3 «Об информации, информационных технологиях и защите информации» [18] информация - это сведения (сообщения, данные) о лицах, предметах, фактах, событиях, явлениях и процессах независимо от формы их представления. Такое определение полностью охватывает юридический характер этого феномена.
По сравнению с ранее действовавшим Федеральным законом от 20 февраля 1995 г. № 24-Ф3, в котором информация означала сведения о лицах, предметах, фактах, событиях, явлениях и процессах независимо от формы их проявления, в новой редакции, действительно, полностью охвачен юридический характер данного понятия.

В приведенном контексте законов Республики Таджикистан «Об информатизации» от 06.08.2001 «Об информации» от 10.05.2002 и «О праве на доступ к информации» от 18.06.2008 информация становится универсальным понятием, которое обозначает любые сведения о ком-либо или о чем-либо, получаемые из любого источника в любой форме: письменной, устной, визуальной и т.п. В данном контексте под сведениями законодатель понимает реальные объекты социальной жизни: лица, предметы, факты, события, явления, а также разные процессы. Таким образом, эти сведения могут служить как объект познания и как ресурс пополнения информационной базы. Исследуя окружающую действительность, мы получаем сведения и тем самим пополняем свои знания.

Таким образом, сопоставляя формулировки понятия «информация» в законодательстве Республики Таджикистан и Российской Федерации, мы выявляем, что они имеют единый смысл и в дальнейшем дополняют друг друга.

При взаимодействии информации и общества происходит изменение социально регулирующих средств (морали, нравственности, традиции, религии и, конечно, права). Последствия этих изменений повлекут структурные изменения всего общества. Повсеместное внедрение информационных технологий и основанных на них информационных телекоммуникационных сетей приводит к формированию информационного (виртуального) пространства. Данное явление требует упорядочения и системной организации самой информации.

Развитие информационных технологий требует совершенствовать информационное законодательство любого государства, в том числе и Республики Таджикистан. Указанные процессы поставили перед законодателем проблему эффективного юридического упорядочения общественных отношений в информационной сфере. За последнее десятилетие в Таджикистане было принято значительное число новых нормативных правовых актов ${ }^{1}$, внесены изменения и дополнения в отраслевые нормативные правовые акты ${ }^{2}$, которые направлены на регламентацию общественных отношений в сфере информационных правоотношений.

\section{ПРИМЕЧАНИЯ}

\footnotetext{
${ }^{1}$ Кроме вышеуказанных нормативных правовых актов в дальнейшем в Таджикистане были приняты следующие нормативные правовые акты, которые регулируют общественные отношения в сфере информационных правоотношений: Закон Республики Таджикистан «О национальном архивном фонде и архивных учреждениях» от 13.11.1998 [19]; Закон Республики Таджикистан «О библиотечной деятельности» от 01.08.2003 [20]; Закон Республики Таджикистан «Об электронном документе» от 23.04.2002 [21]; Закон Республики Таджикистан «О защите информации» от 02.12.2002 [22]; Закон Республики Таджикистан «Об электронной цифровой подписи» от 30.07.2007 [23]; Закон Республики Таджикистан «О периодической печати и других средствах массовой информации» от 19.03.2013 [24]. Помимо вышеупомянутых законодательных актов принят ряд подзаконных актов Президента и Правительства Республики Таджикистан в этой сфере.

${ }^{2}$ В связи с информатизацией общества и принятием нормативных правовых актов для регулирования информационных правоотношений были внесены изменения и дополнения в ряд отраслевых законодательных актов, например: Закон Республики Таджикистан «Об обращении граждан» от 14 декабря 1996 г. [25]; Уголовный кодекс Республики Таджикистан от 21 мая 1998 г. [26]; Закон Республики Таджикистан «О телевидении и радиовещании» от 14 ноября 1996 г. [27].
} 


\section{ЛИТЕРАТУРА}

1. Теория государства и права : учеб. / А.С. Пиголкин, А.Н. Головистикова, Ю.А. Дмитриева ; под ред. А.С. Пиголкина, Ю.А. Дмитриева. 2е изд., перераб. и доп. М. : Юрайт; ИД Юрайт, 2010. 744 с.

2. Венгеров А.Б. Теория государства и права : учеб. 6-е изд., стереотип. М. : Омега-Л, 2009. 607 с.

3. Сативалдыев Р.Ш. Теория государства и права : учеб. (на тадж. яз.). Душанбе : Империал-Групп, 2014.720 с.

4. Комаров С.А. Общая теория государства и права : учеб. 7-е изд. СПб. : Питер, 2008. 512 с.

5. Чубукова С.Г., Элькин В.Д. Основы правовой информатики (юридические и математические вопросы информатики) : учеб. пособие. 2-е изд., испр., доп. / под ред. М.М. Рассолова, В.Д. Элькина. М. : КОНТРАКТ, 2007. 287 с.

6. Философский словарь / под ред. И.Т. Фролова. 6-е изд., перераб. и доп. М. : Политиздат, 1991. 560 с.

7. Краткий словарь по философии / под ред. И.В. Блауберга, И.К Пантина. 3-е изд., дораб. и доп. М. : Политиздат, 1979. 413 с.

8. Гаврилов О.А. Курс правовой информатики : учеб. для вузов. М. : НОРМА (НОРМА-ИНФРА-М), 2002.432 с.

9. Филинов Е.Н. Проблемы информатики и информационные технологии // Системы и средства информатики / под ред. И.А. Соколова. М. : ФИЗМАТЛИТ, 2000. Вып. 10.320 с.

10. Воройский Ф.С. Информатика. Новый систематизированный толковый словарь-справочник (Введение в современные информационные и телекоммуникационные технологии в терминах и фактах). 3-е изд., перераб. и доп. М. : ФИЗМАТЛИТ, 2003.760 с.

11. Зейналов 3.3. Проблемы определения информации как объекта информационных правоотношений // Информационное право. 2010. № 1. С. 6-9 // СПС «Консультант Плюс» (дата обращения: 24.03.2010).

12. Копылов В.А. Информационное право : учеб. 2-е изд., перераб. и доп. М. : Юристь, 2004. 512 с.

13. Минбалеев А.В. Система информации: теоретико-правовой анализ : автореф. дис. ... канд. юрид. наук. Челябинск, 2006.33 с.

14. Закон Республики Таджикистан «Об информатизации» (Ахбори Маджлиси Оли Республики Таджикистан. 2001. № 7. Ст. 502; 2005. № 12. Ст. 639).

15. Закон Республики Таджикистан «Об информации» (Ахбори Маджлиси Оли Республики Таджикистан. 2002. № 4. Ч. 2. Ст. 320).

16. Закон Республики Таджикистан «О праве на доступ к информации» (Ахбори Маджлиси Оли Республики Таджикистан. 2008. № 6. Ст. 469).

17. Меликов У.А. Правовое регулирование предпринимательской деятельности при создании и распространении средств массовой информации. Душанбе, 2011. 192 с

18. Российская газета. 2006. 29 июля. № 165

19. Закон Республики Таджикистан «О национальном архивном фонде и архивных учреждениях» от 13.11 .1998 (Ахбори Маджлиси Оли Республики Таджикистан. 1998. № 23-24. Ст. 326; 2008. № 12. Ст. 1018).

20. Закон Республики Таджикистан «О библиотечной деятельности» от 01.08.2003 (Ахбори Маджлиси Оли Республики Таджикистан. 2003. № 8. Ст. 455; 2008. № 12. Ч. 2. Ст. 1013).

21. Закон Республики Таджикистан «Об электронном документе» от 23.04. 2002 (Ахбори Маджлиси Оли Республики Таджикистан. 2002. № 4. Ч. 1. Ст. 308; 2005. № 12. Ст. 637).

22. Закон Республики Таджикистан «О защите информации» от 02.12.2002 (Ахбори Маджлиси Оли Республики Таджикистан. 2002. № 11. Ст. 696; 2005. № 12. Ст. 646).

23. Закон Республики Таджикистан «Об электронной цифровой подписи» от 30.07 .2007 (Ахбори Маджлиси Оли Республики Таджикистан. 2007. № 6. Ст. 532).

24. Закон Республики Таджикистан «О периодической печати и других средствах массовой информации» от 19.03.2013 (Ахбори Маджлиси Оли Республики Таджикистан. 2013. № 3. Ст. 200).

25. Закон Республики Таджикистан «Об обращении граждан» от 14 декабря 1996 г. (Ахбори Маджлиси Оли Республики Таджикистан. 1996. № 24. Ст. 368; 1998. № 10. Ст. 79; 2006. № 11. Ст. 469; 2007. № 7. Ст. 666).

26. Уголовный кодекс Республики Таджикистан от 21 мая 1998 г. (Ахбори Маджлиси Оли Республики Таджикистан. 1998. № 9. Ст. 68, 69; № 22, Ст. 306; 1999. № 12. Ст. 316; 2001. № 4. Ст. 149-167; 2002. № 11. Ст. 675, 750; 2003. № 8. Ст. 456, 468; 2004. № 5. Ст. 346; № 7. Ст. 453; 2005. № 3. Ст. 126; № 7. Ст. 399; № 12. Ст. 640; 2007. № 7. Ст. 665; 2008. № 1, ч. 1. Ст. 3; № 6. Ст. 444, 447; № 10. Ст. 803; № 12, ч. 1. Ст. 986; Ч. 2. Ст. 992; 2009. № 3. Ст. 80).

27. Закон Республики Таджикистан «О телевидении и радиовещании» от 14 ноября 1996 г. (Ахбори Маджлиси Оли Республики Таджикистан. 1996. № 24. Ст. 408; 1998. № 10. Ст. 76; 1999. № 6. Ст. 166; 2000. № 11. Ст. 521; 2001. № 7. Ст. 481; 2004. № 2. Ст. 39; 2006 . № 4. Ст. 197).

Статья представлена научной редакцией «Право» 19 января 2017 г.

\section{INFORMATION AS THE MAIN OBJECT OF INFORMATION LEGAL RELATIONS: THEORETICAL AND PRACTICAL ASPECTS}

Vestnik Tomskogo gosudarstvennogo universiteta - Tomsk State University Journal, 2017, 415, $212-216$.

DOI: 10.17223/15617793/415/30

Gaybullo A. Shokirov, Tajik State University of Law, Business and Politics (Khujand, Tajikistan). E-mail: Shga1959@mail.ru

Keywords: information; informatics; computing equipment; objects of legal relations; information law; information legislation.

In this article the concept and essence of information in the society and information as the main object of informational legal relations are analyzed. The development of the role of information and information technology in modern society is associated with the intensive development of basic and applied research in different areas of science, and information connects them. Information is studied in terms of knowledge representation in technical, economic and social areas. It is obvious that computing equipment is able to solve a wide variety of problems and tasks connected with the collection, processing and use of information. In practice, information is inside information technology, and technical devices we use are computer devices. The main object of study of sciences, including informatics, is information. Nowadays, informatics becomes applied. With the development of our knowledge of the world we live in, our understanding of information changes. Many modern ideas about the content of information are connected with the person and their ability to think. Thus, in this article the definition of this concept is considered, its essence and content is described from different positions. The definition was analyzed in the context of the concept "object of legal relations". Different points of views of researchers on this concept were analyzed, because on the basis of the views expressed it can be determined that the term "object of legal relations" is understood as meaning of the existence of these relations. Why do subjects of law enter legal relations, act in them, exercising their rights and responsibilities? The object of information relations is information. The article further describes the concept and special features of information, especially in terms of strong traditions of considering information on the basis of philosophical categories of reflection and difference, i.e. diversity. In addition, there is a notion of information in informatics, too. The concept 
of information was analyzed in the context of information legislation of the Republic of Tajikistan and of its correlation with information legislation of the Russian Federation. It was found they have a similar sense and replenish each other.

\section{REFERENCES}

1. Pigolkin, A.S. \& Dmitriev, Yu.A. (eds) Teoriya gosudarstva i prava [Theory of State and Law]. 2nd ed. Moscow: Yurayt; ID Yurayt.

2. Vengerov, A.B. (2009) Teoriya gosudarstva i prava [Theory of State and Law]. 6th ed. Moscow: Omega-L.

3. Sativaldyev, R.Sh. (2014) Teoriya gosudarstva i prava [Theory of State and Law]. Dushanbe: Imperial-Grupp. (In Tajik).

4. Komarov, S.A. (2008) Obshchaya teoriya gosudarstva i prava [General Theory of State and Law]. 7th ed. St. Petersburg: Piter.

5. Chubukova, S.G. \& El'kin, V.D. (2007) Osnovy pravovoy informatiki (yuridicheskie i matematicheskie voprosy informatiki) [Fundamentals of legal informatics (Legal and mathematical questions of informatics)]. 2nd ed. Moscow: KONTRAKT.

6. Frolov, I.T. (ed.) (1991) Filosofskiy slovar' [Philosophical Dictionary]. 6th ed. Moscow: Politizdat.

7. Blauberg, I.V. \& Pantin, I.K. (eds) (1979) Kratkiy slovar' po filosofii [Concise Dictionary of Philosophy]. 3rd ed. Moscow: Politizdat.

8. Gavrilov, O.A. (2002) Kurs pravovoy informatiki [Legal informatics course]. Moscow: NORMA (NORMA-INFRA-M).

9. Filinov, E.N. (2000) Problemy informatiki i informatsionnye tekhnologii [Problems of informatics and information technologies]. In: Sokolov, I.A. (ed.) Sistemy i sredstva informatiki [Informatics systems and tools]. Vol. 10. Moscow: FIZMATLIT.

10. Voroyskiy, F.S. (2003) Informatika. Novyy sistematizirovannyy tolkovyy slovar'-spravochnik [Informatics. New Systematic Explanatory Dictionary]. 3rd ed. Moscow: FIZMATLIT.

11. Zeynalov, Z.Z. (2010) Problemy opredeleniya informatsii kak ob"ekta informatsionnykh pravootnosheniy [Problems of definition of information as an object of information legal relations]. Informatsionnoe pravo. 1. pp. 6-9.

12. Kopylov, V.A. (2004) Informatsionnoe pravo [Information Law]. 2nd ed. Moscow: Yurist'.

13. Minbaleev, A.V. (2006) Sistema informatsii: teoretiko-pravovoy analiz [Information system: theoretical and legal analysis]. Abstract of Law Cand. Diss. Chelyabinsk.

14. Republic of Tajikistan. (2001) Law of the Republic of Tajikistan “On Information”. Akhbori Madzhlisi Oli Respubliki Tadzhikistan. 7. Art. 502. (In Russian).

15. Republic of Tajikistan. (2002) Law of the Republic of Tajikistan “On Information”. Akhbori Madzhlisi Oli Respubliki Tadzhikistan. 4:2. Art. 320. (In Russian).

16. Republic of Tajikistan. (2008) Law of the Republic of Tajikistan “On the Right to Access Information”. Akhbori Madzhlisi Oli Respubliki Tadzhikistan. 6. Art. 469. (In Russian).

17. Melikov, U.A. (2011) Pravovoe regulirovanie predprinimatel'skoy deyatel'nosti pri sozdanii i rasprostranenii sredstv massovoy informatsii [Legal regulation of business in creating and distributing media]. Dushanbe.

18. Rossiyskaya gazeta. (2006). 29 July. 165.

19. Republic of Tajikistan. (1998) Law of the Republic of Tajikistan "On National Archive Fund and archive institutions" of 13 November 1998. Akhbori Madzhlisi Oli Respubliki Tadzhikistan. 23-24. Art. 326. (In Russian).

20. Republic of Tajikistan. (2003) Law of the Republic of Tajikistan “On the library activity" of 01 August 2003. Akhbori Madzhlisi Oli Respubliki Tadzhikistan. 8. Art. 455. (In Russian).

21. Republic of Tajikistan. (2002) Law of the Republic of Tajikistan "On Electronic Document” of 23 April 2002. Akhbori Madzhlisi Oli Respubliki Tadzhikistan. 4:1. Art. 308. (In Russian).

22. Republic of Tajikistan. (2001) Law of the Republic of Tajikistan “On the protection of information” of 02 December 2002. Akhbori Madzhlisi Oli Respubliki Tadzhikistan. 11. Art. 696. (In Russian).

23. Republic of Tajikistan. (2007) Law of the Republic of Tajikistan "On electronic digital signature" of 30 July 2007. Akhbori Madzhlisi Oli Respubliki Tadzhikistan. 6. Art. 532. (In Russian).

24. Republic of Tajikistan. (2013) Law of the Republic of Tajikistan "On the periodical press and other mass media" of 19 March 2013. Akhbori Madzhlisi Oli Respubliki Tadzhikistan. 3. Art. 200. (In Russian).

25. Republic of Tajikistan. (1996) Law of the Republic of Tajikistan “On citizens' appeals” of December 14, 1996. Akhbori Madzhlisi Oli Respubliki Tadzhikistan. 24. Art. 368. (In Russian).

26. Republic of Tajikistan. (1998) The Criminal Code of the Republic of Tajikistan, of 21 May 1998. Akhbori Madzhlisi Oli Respubliki Tadzhikistan. 9. Art. 68, 69. (In Russian).

27. Republic of Tajikistan. (1996) Law of the Republic of Tajikistan "On Television and Radio Broadcasting" of 14 November 1996. Akhbori Madzhlisi Oli Respubliki Tadzhikistan. 24. Art. 408. (In Russian). 